\title{
Evaluation of Technical and Protective Functions; Radiology Department Staff of Zahedan University of Medical Sciences
}

\author{
Fateme Zakieh Tohidi ${ }^{1}$, Hadi Nakhzari Moghadam ${ }^{1}$, Sahar Azari-Mofrad ${ }^{2}$, Saeed Ghasemi ${ }^{3}$, Seideh \\ Zeinab Almasi ${ }^{4}$ and Mohadeseh Tohidi ${ }^{5,{ }^{*}}$ \\ ${ }^{1}$ Medical Physics Department, Faculty of Medicine, Zahedan University of Medical Sciences, Zahedan, Iran \\ ${ }^{2}$ Radiology Department, Faculty of Paramedical Sciences, Zahedan University of Medical Sciences, Zahedan, Iran \\ ${ }^{3}$ Vali-e-Asr Hospital, Birjand University of Medical Sciences, Birjand, Iran \\ ${ }^{4}$ Health Promotion Research Center, Zahedan University of Medical Sciences, Zahedan, Iran \\ ${ }^{5}$ Physics Department, Payame Noor University of Mashhad, Mashhad, Iran \\ "Corresponding author: Physics Department, Payame Noor University of Mashhad, Mashhad, Iran. Email: fm.tohidi@yahoo.com
}

Received 2019 August 17; Revised 2019 November 30; Accepted 2019 December 10.

\begin{abstract}
Background: Maintaining patients' safety is a basic professional role of radiographers. Therefore, the present study aimed to evaluate the technical, protective, and technological operation of interventional radiologists.

Objectives: The current study aimed to determine the protective and technical performance of radiographers and their knowledge and expertise.

Methods: In this descriptive-analytical study, 60 radiographers working in radiology wards of hospitals affiliated to the Zahedan University are included. A checklist whose reliability and validity were previously established was used to collect data. For the radiography staff, 17 technical and 12 protective items were checked and recorded during three work shifts. Data were analyzed by SPSS.

Results: The performance score of 27 males (45\%) and 33 females (65\%) was assessed. Seven factors of radiology staff, including gender, employment status, age, work experience, number of shifts, Work Shift, and Education, were evaluated, and that number of shifts was statistically significant.

Conclusions: The radiographers' awareness of technical and protective principles was at a medium level. Increasing attention to the quality of academic training and continuous education is necessary.
\end{abstract}

Keywords: Radiographs, Radiation Protection, Radiography Techniques

\section{Background}

Radiology departments have an important role in diagnosing patients' problems. Radiographers have two main roles in taking diagnostic images and in protecting the patients against radiation. Nowadays, X-ray imaging is one of the most frequently used and developing methods for medical diagnosis, which provides necessary information for making therapeutic decisions. Although X-ray is a valuable medical tool that provides several benefits, it's also an important source of exposure to artificial radiation (1-5). Since the consequences of exposure to ionizing radiation are well-documented, caution should be taken when using $\mathrm{x}$-ray radiation, and ALARA law should be observed to minimize unnecessary radiation of both patients and personnel $(6,7)$. Radiographers should pay attention to a wide range of factors to perform radiography to maintain the quality of images; meanwhile, they should minimize pa- tients' attention to radiation $(8,9)$. The European Union has developed a program entitled "guidelines for quality of radiographic quality" and recommended countries to follow its guidelines. Exposure to an excessive amount of ionizing radiation may negatively influence the genes, hematopoietic cells, and central nerves (10-12). Besides, it may cause problems for the surface of the body (such as burns, cataracts, and scales) (13). Factors that contribute to the absorption rate of radiation are determined. Therefore, through careful planning, the percentage of radiography and radiation absorption should be reduced (14, 15); Increasing the awareness of radiographers about currently available guidelines for reducing the absorption of radiations has a significant influence on protecting the patients against ionizing radiation. Moreover, as knowledge forms the behaviors, unfamiliarity with safety measures may cause harmful results for both patients and radiog- 
raphers. Therefore, the awareness of radiographers with safety measures is necessary to minimize exposures to radiation, which guarantees their proper functioning. The literature (e.g. Almen et al (16) and Muhogora et al. (17)) indicates that to enhance the quality of radiography images, it's necessary to observe the principles noted in this guideline. In this regard, Krutz (18), Gogos (19), Ononugbo and Nwokeoji (20), and Almalki (21) have performed related research in this field. These studies have shown that teaching technical and protective principles could improve the performance of radiographers (18-21).

Alipoor et al. (22), Davoudian Talib et al., and Borhani and Alizadeh also acknowledged that staff performance was not optimal, and they required further education and retraining to raise their awareness (22-24).

\section{Objectives}

The current study aimed to investigate the protective and technical performance of radiographers and their knowledge and expertise in this field. The statistical population of the study was all staff of radiographic centers in hospitals affiliated to the Zahedan University of Medical Sciences (ZUMS).

According to the results of this research, to raise awareness and improve the level of performance of staff, the status quo should first be investigated to provide a basis for future decisions. Therefore, the present study also aimed to determine the performance and knowledge of the staff of the radiology departments regarding the principles of radiography and hints. All protective measures were observed.

\section{Methods}

This cross-sectional descriptive-analytic study was conducted to determine the protective and technical performance of radiologists and their knowledge and expertise in this field. The statistical population was all staff working in radiology centers of hospitals affiliated to ZUMS (in total, 60 staff). To collect data on personnel performance, a checklist was used to construct a construct that contained 17 technical functions and 12 protective functions. Each performance was scored from zero or one based on the subjects' performance. For the technical section, the total score ranges from zero to 17 , and for the protective function, it ranges from zero to 12 . To check the validity of this checklist, opinions of three radiographers's were used, which was approved.

\subsection{Reliability and Validity of the Questionnaire}

To assess the reliability of the checklist, the questionnaire was completed by 10 radiologists and freelance researchers. Again, they filled the questionnaire a month later. Then, to evaluate the reliability the alpha Cronbach coefficient was calculated, which was equaled to $79 \%$, which confirmed the reliability.

\subsection{Ethical Approval}

As the checklist was anonymous, there was no ethical prohibition. Participation was voluntary, and participants were informed about the confidentiality of information. All ethical considerations were observed in the present study.

\subsection{Data Collection}

The items in the checklist were reviewed and evaluated by a radiologist in three different shifts. To measure the level of awareness of the staff about the protective and technical principles, a questionnaire comprised of 12 items that were arranged in two parts was developed. The questionnaire was filled through face-to-face interviews. Each true answer had 1 score, and an incorrect answer had a zero score; the total score ranges from zero to 12 . To collect the data, the researcher was attending radiology departments without any knowledge of the personnel and recorded the performance of each of the personnel in the morning, evening, and night shifts by the checklist.

\subsection{Statistical Analyses}

Data were analyzed by SPSS (version 15) using descriptive statistics such as correlation, independent t-test, oneway ANOVA, and Tukey test. Statistical significance was considered when $P$ value $<0.05$.

\section{Results}

\subsection{Technical and the Protective Mean Score}

A total of 60 personnel participated in the present study. The mean score of the technical and protective parts was $14.32 \pm 1.78$, and $10.05 \pm 2.06$, respectively. The highest and lowest percentage of correct responses in the protective part were $96.7 \%$ and $63.3 \%$, respectively, and for the technique part, the values were $100 \%$ and $30 \%$, respectively.

\subsection{Evaluation of Technical and Protective Mean Score Accord-} ing to 7 Factors

Of 60 participants, 27 (45\%) were males, and 33 (65\%) were females. The results of the seven factors of radiology staff, including gender, employment status, age, work experience, number of shifts, work shift, and education, are listed in the following tables (Tables 1-3). 
Table 1. Mean and Standard Deviation of the Correct Response Score of the Subjects From Radiologists' Awareness of the Technical and Protective Principles According to the Employment Status and Gender Based on the $t$-test

\begin{tabular}{|c|c|c|c|c|c|}
\hline \multirow{2}{*}{ Variable } & \multirow{2}{*}{$\begin{array}{l}\text { Demographic } \\
\text { Characteristics }\end{array}$} & \multicolumn{2}{|c|}{ Average Technique } & \multicolumn{2}{|c|}{ Protection } \\
\hline & & Average & Standard Deviation & Average & Standard Deviation \\
\hline \multirow{2}{*}{ Gender } & Female & 14.36 & 1.59 & 9.78 & 2.04 \\
\hline & Male & 14.26 & 2.03 & 10.40 & 2.12 \\
\hline \multirow{2}{*}{ Employment status } & Project & 14.18 & 2.06 & 9.60 & 2.22 \\
\hline & Other & 14.38 & 1.68 & 10.21 & 2.00 \\
\hline
\end{tabular}

Table 2. Relationship Between the Variables the Correct Answer of the Subjects From the Awareness of Radiographers About the Technical and Protective Principles Based on the Number of Shifts, Age and Work Experience Based on the Correlation Test

\begin{tabular}{lcc}
\hline Variable & $\begin{array}{c}\text { The Degree of Technical } \\
\text { Relation }\end{array}$ & $\begin{array}{c}\text { Degree of Protection } \\
\text { Relationship }\end{array}$ \\
\hline Number of shifts & $-0.299^{\mathrm{a}}$ & -0.044 \\
Age & 0.02 & 0.140 \\
Work experience & $-0 / 042$ & 0.155 \\
\hline
\end{tabular}

${ }^{\mathrm{a}}$ The number of shifts with a technical function has a significant inverse relationship.

\section{Discussion}

The current study aimed to investigate the knowledge and practice of personnel working in radiology departments affiliated to the ZUMS regarding the protective and technical principles. The findings indicated that the knowledge of the staff in the two investigated areas is high. As the negative consequences of exposure with ionizing radiation is well-documented, staff of radiology departments have a mean working age of about 10 years. The mean working age of personnel was 8.9 years; which indicates compliance with the radiation protection law. Also, the protection and technical principles defined for both male and female personnel were equal to published standards. This result is influenced by the project forces, which are a significant number, as well as the continuation of postgraduate studies with a long work experience, because, in recent years, Zahedan University of Medical Sciences is attracting a discontinuous radiology student Regarding the personnel performance in the technical area, the highest percentage was related to the "providing rapid services to the emergency patient" (100\%), which indicates the importance given to patients in emergency situations, and the lowest percentage belonged to the "deep exhalation in simple abdominal radiography" (30\%), This result can be due to the high number of patients referred to the emergency department and the importance of taking care of them and increasing the skill of the staff. For the protective part, the highest score belonged to the "closing the door when working with the tube" (96.7\%), and the lowest percentage was for the "use of lead shield" (63.3\%).

The intra-comparison of mean scores of protective and technical performance revealed no significant difference between males and females (Table 1); Compared to the results reported by Tavakoli et al. (25), in the present study, in the protective area, males had a better performance, while in the technical field, females had a better performance. As shown in Table 1, the employment status didn't have a significant influence on the performance of the staff. It should be noted that about one-third of the staff were project planners, and due to up-to-date information and wing motivations for learning and absorption, they had a significant impact on the desired results.

Radiologists' protective performance was directly associated with their years of experience, but for technical performance, such association was inverse (Table 2). Although these associations were not statistically significant but, probably, the higher the years of experience, the better would be the performance. The performance of radiologists in the fields of protective and technical was directly associated with their age. So that, the older was the person, the higher was the years of experience, and, consequently, the better was the performance (Table 2), Which is consistent with the results reported by Rahimi et al. (26).

Comparing the performance of staff by considering their university degree revealed that those with an MSc degree had a better performance than those with a bachelorette degree or lower (Table 3), Comparing technical and protective performance by degree, it indicated better performance of master's staff than others; this is taken from their awareness and more information. This issue is also reported by other studies $(22,23)$. As university education decreases, so does the desired outcome (25).

The highest technical and protective performances were observed at night shifts (Table 3), which can be attributed to the lower workload of the staff. The present study had other findings, including higher technical performance and personnel protection among those who had less working shifts; the inverse association between the number of shifts and the efficiency of staff (27); nevertheless, no association was found between the type of the shift 
Table 3. Mean and Standard Deviation of the Correct Response Score of the Subjects From Radiologists' Awareness of the Technical and Protective Principles According to the Type of Educational Qualification and Work Shift Based on One-Way ANOVA

\begin{tabular}{|c|c|c|c|c|c|}
\hline \multirow{2}{*}{ Variable } & \multirow{2}{*}{$\begin{array}{l}\text { Demographic } \\
\text { Characteristics }\end{array}$} & \multicolumn{2}{|c|}{ Technique } & \multicolumn{2}{|c|}{ Protection } \\
\hline & & Average & Standard deviation & Average & Standard deviation \\
\hline \multirow{3}{*}{ Education } & Associate degree & 14.59 & 2.06 & 10.33 & 2.11 \\
\hline & Bachelor & 14.03 & 1.64 & 9.69 & 2.01 \\
\hline & MA & 16.00 & 1.88 & 12.00 & 0.00 \\
\hline \multirow{7}{*}{ Work Shift } & Morning & 15.15 & 1.51 & 10.38 & 2.43 \\
\hline & Evening & 14.50 & 0.70 & 8.50 & 0.70 \\
\hline & Night & 15.25 & 0.50 & 10.67 & 1.52 \\
\hline & Morning to evening & 14.31 & 1.29 & 9.79 & 1.93 \\
\hline & Morning to night & 13.00 & 2.58 & 10.60 & 1.94 \\
\hline & Evening-night & 14.00 & 0.00 & 10.00 & 0.00 \\
\hline & $\begin{array}{l}\text { Morning to } \\
\text { evening-night }\end{array}$ & 13.75 & 2.32 & 10.00 & 2.32 \\
\hline
\end{tabular}

(i.e. morning, evening, and nights) the staffs' performance (Tables 2 and 3).

\subsection{Conclusions}

In general, the quality of performance and knowledge of the staff was acceptable. However, as ionizing radiation is associated with increased health risks, special attention should be paid to this issue in educational programs, continuous education programs, and supervision programs. Besides, it should be noted that using protective equipment can effectively reduce the absorption rate for both patients and the staff while maintaining the quality of images. Holding seminars, training courses, and continuous education programs can effectively increase the awareness, attitudes, and practice of the staff. Which in turn results in increased use of protective measures and better performance of the staff.

\section{Acknowledgments}

We acknowledge the collaboration of hospitals affiliated to the ZUMS.

\section{Footnotes}

Authors' Contribution: Study concept and design: Fateme Zakieh Tohidi, Hadi Nakhzari Moghadam, Saeed Ghasemi, and Mohadeseh Tohidi. Acquisition of data: Fateme Zakieh Tohidi and Sahar Azari-Mofrad. Statistical analysis: Fateme Zakieh Tohidi and Seideh Zeinab Almasi. Analysis and interpretation of data: Fateme Zakieh Tohidi, Hadi Nakhzari Moghadam, Sahar Azari-Mofrad, and Mohadeseh Tohidi. Drafting of the manuscript and critical revision of the manuscript for important intellectual content: Fateme Zakieh Tohidi, Sahar Azari-Mofrad, and Mohadeseh Tohidi.

Conflict of Interests: The authors declare no conflict of interest.

Ethical Approval: This study is approved by the ethics committee of the ZUMS (code: IR.ZAUMS.REC.1397.460).

Funding/Support: This study is sponsored by the Faculty of Medicine of the Zahedan University of Medical Sciences.

\section{References}

1. Artschan RE, Brettle DS, Chase K, Fender A, Howells PG, Buchan S. An investigation of the radiation doses to the lower legs and feet of staff undertaking interventional procedures. $\mathrm{Br} \mathrm{J} \mathrm{Ra}$ diol. 2014;87(1038):20130746. doi: 10.1259/bjr.20130746. [PubMed: 24678856]. [PubMed Central: PMC4075555].

2. Kuon E, Schmitt M, Dahm JB. Significant reduction of radiation exposure to operator and staff during cardiac interventions by analysis of radiation leakage and improved lead shielding. Am J Cardiol. 2002;89(1):44-9. doi: 10.1016/s0002-9149(01)02161-0. [PubMed 11779521].

3. Sanchez RM, Vano E, Fernandez JM, Rosales F, Sotil J, Carrera F, et al. Staff doses in interventional radiology: a national survey. J Vasc Interv Radiol. 2012;23(11):1496-501. doi: 10.1016/j.jvir.2012.05.056. [PubMed: 22832138].

4. Sarti M, Brehmer WP, Gay SB. Low-dose techniques in CT-guided interventions. Radiographics. 2012;32(4):1109-19. discussion 1119-20. doi: 10.1148/rg.324115072. [PubMed: 22786997].

5. Shortt CP, Al-Hashimi H, Malone L, Lee MJ. Staff radiation doses to the lower extremities in interventional radiology. Cardiovasc Intervent Radiol. 2007;30(6):1206-9. doi: 10.1007/s00270-007-9071-0. [PubMed: 17533541].

6. Siegel JA, Brooks AL, Fisher DR, Zanzonico PB, Doss M, O'Connor MK, et al. A Critical Assessment of the Linear No-Threshold Hypothesis: Its Validity and Applicability for Use in Risk Assess- 
ment and Radiation Protection. Clin Nucl Med. 2019;44(7):521-5. doi: 10.1097/RLU.0000000000002613. [PubMed: 31107746]

7. Moore QT. An Interdisciplinary Approach to Improving Radiation Protection in Digital Radiography. Radiol Technol. 2016;88(1):9-17. [PubMed: 27601688].

8. Fraczek M, Guzinski M, Morawska-Kochman M, Nelke KH, Krecicki T. Nasal endoscopy: an adjunct to patient selection for preoperative low-dose CT examination in chronic rhinosinusitis. Dentomaxillo fac Radiol. 2016;45(8):20160173. doi: 10.1259/dmfr.20160173. [PubMed: 27635789]. [PubMed Central: PMC5595023].

9. Tonkopi E, Duffy S, Abdolell M, Manos D. Diagnostic Reference Levels and Monitoring Practice Can Help Reduce Patient Dose From CT Examinations. AJR Am J Roentgenol. 2017;208(5):1073-81. doi: 10.2214/AJR.16.16361. [PubMed: 28245142].

10. Bazrafshan E, Mohamadi JL, Naroei KH, Parvaneh HR, Mohamadrigi F. Survey of health and protection status of radiology centers covered by Zahedan University of Medical Sciences during 2010-2011. J Zabol Univ Med Sci Health Serv. 2012;4(1):29-38.

11. Fardid R, Bahreyni Toossi MT, Rezaee A, nabavi AS, Rafatpanah H. Expression of IFNg and TGFb1 genes can distinguish radiation workers from the normal population. Int J Low Radiat. 2014;9(5/6). doi 10.1504/ijlr.2014.068282.

12. Tohidi FZ, Toosi Bahrayni MH, Azimian H, Khademi S, Fardid R, Sarab Anani GH. The gene expression level of p53 and p21 in mouse brain exposed to radiofrequency field. Int J Radiat Res. 2015.

13. Motevalli SM, Borhanazad AM. Study of occupational exposure of medical centers in Guilan province. J Guilan Univ Med Sci. 2014;22(88):41-8.

14. Archer BR, Wagner LK. Protecting patients by training physicians in fluoroscopic radiation management. I Appl Clin Med Phys. 2000;1(1):32-7. doi: 10.1120/jacmp.v1i1.2653. [PubMed: 11674817]. [PubMed Central: PMC5726161].

15. Reiner BI, Siegel EL, Carrino JA, Goldburgh MM. SCAR Radiologic Technologist Survey: analysis of the impact of digital technologies on productivity. J Digit Imaging. 2002;15(3):132-40. doi: 10.1007/s10278-002 0021-8. [PubMed: 12481227]. [PubMed Central: PMC3613256].

16. Almen A, Tingberg A, Mattsson S, Besjakov J, Kheddache S, Lanhede B et al. The influence of different technique factors on image quality of lumbar spine radiographs as evaluated by established CEC image criteria. Br J Radiol. 2000;73(875):1192-9. doi: 10.1259/bjr.73.875.11144797. [PubMed: 11144797].

17. Muhogora WE, Nyanda AM, Kazema RR. Experiences with the European guidelines on quality criteria for radiographic images in Tanza-
nia.JAppl Clin Med Phys. 2001;2(4):219-26. doi:10.1120/jacmp.v2i4.2601. [PubMed: 11686743]. [PubMed Central: PMC5726009].

18. Kurtz C, Czapp W, Trampe I, Leppek R, Klose KJ. [X-rays taken by radiologists! Influence on a continuous quality improvement process?]. Rofo. 2000;172(4):391-6. doi: 10.1055/s-2000-349. [PubMed:10961226].

19. Gogos KA, Yakoumakis EN, Tsalafoutas IA, Makri TK. Radiation dose considerations in common paediatric X-ray examinations. Pediatr Radiol. 2003;33(4):236-40. doi: 10.1007/s00247-002-0861-x. [PubMed: 12709751].

20. Ononugbo CP, Nwokeoji IE. Radiation Risk Assessment from Background Radiation Exposures in Selected Hospitals in South-South Nigeria. Curr J Appl Sci Technol. 2017:1-13.

21. Almalki AA, Abdul Manaf R, Hanafiah Juni M, Kadir Shahar H, Noor NM, Gabbad A. Educational Module Intervention for Radiographers to Reduce Repetition Rate of Routine Digital Chest Radiography in Makkah Region of Saudi Arabia Tertiary Hospitals: Protocol of a QuasiExperimental Study. JMIR Res Protoc. 2017;6(9). e185. doi: 10.2196/resprot.8007. [PubMed: 28951379]. [PubMed Central: PMC5635235].

22. Alipoor R, Mousavian G, Abbasnezhad A, Mousavi SF, Haddadi G. Knowledge, attitude, and performance of radiographers about the principles of radiation protection and following protective standards in medical imaging centers of hospitals in Fasa in 2015. J Fasa Univ Med Sci. 2016;5(4):564-70.

23. Badiee Nejad A, Beit Abdollah M, Akbari G. Assessment of awareness, performance, and attitudes of radiographers toward radiological protective principles in Khuzestan, Irangraphers. J Health Res Commun. 2015;1(3):16-24.

24. Borhani PA. Investigating the performance of personnel in radiology departments of hospitals affiliated to Kerman University of Medical Sciences Medical Journal of Hormozgan University. J Hygiene Develop. 2002;6(4):51-8.

25. Tavakkoli MR, Tohidi FZ, Sharifzadeh GR, Ghasemi S. An assessment of radiographers' technical and protective performance in hospitals affiliated to Birjand University of Medical Sciences in 2012. J Birjand Univ Med Sci. 2014;21(2):253-9.

26. Rahimi SA, Pourkaveh M. Interventional Radiologists: a Necessary Evaluation of Technical, Protective and Technological Operation. Acta Inform Med. 2016;24(1):20-4. doi: 10.5455/aim.2016.24.20-24. [PubMed: 27041806]. [PubMed Central: PMC4789648].

27. Magnavita N, Fileni A. Association of work-related stress with depression and anxiety in radiologists. Radiol Med. 2014;119(5):359-66. doi: 10.1007/s11547-013-0355-y. [PubMed: 24297590]. 